\title{
REMAKE, HISTORIA E IDEOLOGÍA: HOLLYWOOD Y ADIÓS A LAS ARMAS DE ERNEST HEMINGWAY
}

\section{Remake, History and Ideology: Hollywood and Ernest Hemingway's A Farewell to Arms}

\author{
Dr. Alberto José LENA ORDÓÑEZ \\ Funcionario Docente, España \\ E-mail: alena_ord@yahoo.co.uk \\ (D) http://orcid.org/0000-0001-7893-5496
}

Fecha de recepción del artículo: 29/03/2017

Fecha de aceptación definitiva: 26/04/2017

\begin{abstract}
RESUMEN
En este artículo se analiza la adaptación de la novela Adiós a las armas de Ernest Hemingway producida por David O. Selznick en 1957. Al tratar de comprender el contexto histórico e ideológico en el que fue producida la película, se tiene en cuenta que Selznick parte de una adaptación anterior de la misma realizada por Frank Borzage en 1932. Así, en este trabajo se hace hincapié en el deseo de Selznick de emular y superar la versión de Borzage. Sin embargo, la comparación entre las dos películas pone de manifiesto que la obra de Borzage permanece como una constante referencia en el remake de Selznick, el cual se apoya en la estructura melodramática de la primera adaptación cinematográfica. Finalmente, la producción de Selznick se puede considerar como un ejemplo del papel que desempeña la desbistorización en el remake cinematográfico.
\end{abstract}

Palabras clave: Adiós a las armas; cine de Hollywood; Ernest Hemingway; Primera Guerra Mundial; remake.

\begin{abstract}
This article analyses David O. Selznick's 1957 adaptation of Ernest Hemingway's A Farewell to Arms. In trying to shed light on the historical and ideological context of Selznick's production, it shall be placed emphasis upon the influence of Frank Borzage's previous adaptation of Hemingway's work. This essay will also stress Selznick's ambitions, that is, the fact that he wanted to emulate and improve the former adaptation of the novel. In spite of this, the comparison between both films reveals that the melodramatic structure of Selznick's remake stems from the structure of Borzage's film. Moreover, Selznick's production could be seen as a case in point of the role played by deshistorization in cinematic remake.
\end{abstract}

Key words: A Farewell to Arms; Hollywood cinema; Ernest Hemingway; First World War; remake. 


\section{INTRODUCCIÓN, MARCO TEÓRICO Y METODOLOGÍA}

En 1932, cuando los estudios Paramount adaptaron la obra de Ernest Hemingway Adiós a las armas ( $A$ Farewell to Arms, Frank Borzage), fue el comienzo de una larga y compleja relación entre dicho escritor norteamericano y los estudios de Hollywood. La obra de Borzage representó, además, un gran éxito de taquilla a nivel internacional que sirvió para que, a partir de ese momento, el nombre de Hemingway transcendiera el ámbito minoritario de la literatura modernista norteamericana y se convirtiera, de repente, en una figura pública, asociada con la cultura de masas (Leff, 1999, p. 168). Tras el éxito de la adaptación de Adiós a las armas, Hollywood y la televisión han continuado fijándose en la obra de Hemingway y han sido innumerables las adaptaciones de sus cuentos y novelas hasta el día de hoy.

Hemingway no fue del todo indiferente al cine, aunque no tuviese una gran estima por el séptimo arte, se interesó al menos por conocer la adaptación de algunas de sus obras. Durante los años cuarenta y cincuenta, se sucedieron un enorme número de adaptaciones que gozaron de un gran éxito de taquilla, entre las que destacan ¿Por quién doblan las campanas? (For Whom the Bell Tolls, Sam Wood, 1943), Tener y no tener (To Have and Have Not, Howard Hawks, 1944) y Las nieves del Kilimanjaro (The Snows of Kilimanjaro, Henry King, 1952). Sin embargo, a pesar del gran número y variedad de adaptaciones cinematográficas, Hemingway no se encontraba satisfecho con ninguna de estas, y muchas veces expresó abiertamente que se sentía traicionado por el cine (Hotchner, 2005, pp. 216-218). Sus quejas no eran del todo arbitrarias. Los estudios realizados por Jamie Barlowe (2011), Stanley Corkin (1989), Frank M. Laurence (1982) y Gene D. Phillips (1980), entre otros, revelan las profundas diferencias que separan las obras originales de Hemingway de las adaptaciones cinematográficas realizadas. Estas diferencias se debieron principalmente a problemas de censura, así como a las peculiaridades de dos medios tan diversos como son el cine y la literatura (Barlowe, 2011, pp. 33-34).

En 1957, cuando el productor cinematográfico David O. Selznick decidió hacer un remake de Adiós a las armas, era consciente del profundo desprecio que Hemingway sentía hacía Hollywood y del poco valor que concedía a cualquier adaptación cinematográfica de sus obras. Sin embargo, para Selznick representó todo un reto adaptar a Hemingway. El afamado productor estaba plenamente convencido de que, al final, el autor se sentiría satisfecho de la adaptación cinematográfica de la novela (Selznick, 2000, pp. 488-489). El que fuera el productor de grandes éxitos, tales como Lo que el viento se llevó (Gone with the Wind, Victor Fleming, 1939) y Duelo al sol (Duel in the Sun, King Vidor, 1947) quería demostrar que se podía adaptar una compleja obra literaria a la gran pantalla sin traicionar su calidad literaria y lograr, además, un gran éxito de taquilla. Hay que tener en cuenta que a finales de los años cincuenta Hollywood se encuentra en una gran encrucijada económica. Se trata de un momento histórico difícil para la industria de Hollywood: la competencia de la televisión había hecho disminuir sensiblemente el número de espectadores que acudían a las salas de cine.

Además del reto económico, hay que tener en cuenta que el ego y la ambición de Selznick eran tales que no se contentaba con realizar una adaptación fiel de Adiós a las armas. Quería emular y superar la primera adaptación de dicha novela, realizada por Borzage que gozaba de una gran independencia dentro de la Paramount, lo que le permitió adaptar la novela de Hemingway siendo, al mismo tiempo, fiel a su propio estilo (Dumont, 2006, pp. 176-178; McElhaney, 2003). Selznick había deseado fervientemente producir la versión de Borzage en los años treinta, pero una serie de circunstancias se lo habían impedido. En 1955, Selznick compró a los estudios Warner los derechos de autor de la adaptación realizada por Borzage. En 1946, los estudios Warner habían comprado a la Paramount los derechos de la película y la habían reestrenado en 1949. Selznick no se conformó tan solo con tener los derechos de la película, sino que, además, eliminó de la circulación todas las copias de la versión del 1932: estaba convencido de que su remake se convertiría en la adaptación por antonomasia de la novela 
de Hemingway (Barlowe, 2011, p. 33). Cuando acomete la empresa de adaptar la novela, el productor, obsesionado con ella, ejerce un poder tiránico sobre los directores contratados para llevar a cabo el proyecto. En primer lugar, no deja que John Huston aporte su visión de la novela de Hemingway, lo que ocasiona que abandone el rodaje de la película a los pocos días de su inicio (Huston, 1980, pp. 271-272). Cuando Charles Vidor remplaza a Huston, Selznick concede al director húngaro un reducido margen de maniobra supervisando y revisando escrupulosamente todas las escenas y dándole indicaciones minuciosas acerca de cómo debe fotografiar a los actores y ensayar con ellos antes de rodar. Todo debe responder a un plan que ha sido trazado meses antes con mucha precisión. Antes de rodar en Italia, Selznick había supervisado meticulosamente la adaptación de la obra de Hemingway. Había colaborado durante meses con Ben Hecht en la ardua construcción del guion que muestra una gran variedad de cambios debidos a las dificultades que suponía adaptar el complejo texto de la novela narrado en primera persona (Hecht, 1957). Por lo tanto, el remake de Adiós a las armas no es una producción más del Hollywood de los años cincuenta. Se trata también de la obra cinematográfica de un productor obsesionado con una pieza literaria y que es plenamente consciente de todas las dificultades que conlleva adaptar la novela de Hemingway. Selznick trata de superar esas dificultades siguiendo muy de cerca la exitosa adaptación de Borzage. No en vano, las dos obras tienen como referencia no solo la novela de Hemingway, sino también la adaptación teatral de la misma realizada por Laurence Stallings en 1930.

Teniendo en cuenta las circunstancias que rodean a la adaptación y producción de la novela de Adiós a las armas, el estudio comparado de las dos adaptaciones, la de 1957 y la de 1932 nos ofrece una gran oportunidad para comprender la importancia del remake como un instrumento esencial a la hora de conocer mejor las transformaciones ideológicas de Hollywood a lo largo del periodo clásico. En este análisis comparativo de ambas obras, se tendrá en cuenta que, como apunta Constantine Verevis, el estudio de todo remake debe considerar las condiciones materiales que obligan a la industria de Hollywood a repetir, copiar y alterar sutilmente una serie de contenidos y estructuras narrativas que han tenido éxito en el pasado y que permiten asegurar buenos resultados de taquilla (Verevis, 2006, pp. 34). La adaptación producida por Selznick de Adiós a las armas es además lo que Thomas Leitch denomina un auténtico remake: nace con la idea de emulación, competencia y superación de una obra anterior, siendo consciente de su dimensión intertextual (Leitch, 2002, pp. 142-145). Esta noción de remake propuesta por Leitch se puede aplicar plenamente a la versión de Adiós a las armas realizada en 1957. Como hemos señalado anteriormente, en el momento de acometer la producción de la película, Selznick no solo se afana por ofrecer una visión fiel de la obra de Hemingway, sino que trata de superar la versión de 1932, a la que siempre tuvo como referente.

Finalmente, el estudio comparado de la adaptación producida por Selznick y la dirigida por Borzage de Adiós a las armas nos permitirá comprender la utilidad del remake a la hora de valorar hasta qué punto el contexto histórico afecta a una adaptación cinematográfica de un texto clásico. Siguiendo la metodología empleada por Linda Hutcheon, se hará hincapié en la importancia del contexto histórico en el que se realizan ambas adaptaciones y cómo afecta de manera profunda al contenido de las mismas. Hutchinson utiliza el término deshistorización (Hutcheon, 2006, pp. 158-160) a la hora de analizar el contexto histórico de diferentes remakes. Hutchinson señala que la deshistorización es una práctica habitual en muchas adaptaciones y remakes de Hollywood que recurre a ella a menudo con el fin de eliminar el contenido histórico de determinados temas nacionales o regionales que pueden resultar problemáticos para un público internacional. En este trabajo se mostrará cómo la adaptación realizada por Selznick altera de manera radical el significado histórico de la obra de Hemingway y dicha alteración es, al mismo tiempo, el producto de unas circunstancias determinadas relacionadas con la Guerra Fría. 


\section{MARCO HISTÓRICO}

Adiós a las armas representa una de las novelas más importantes ambientadas en la Primera Guerra Mundial, tanto desde el punto de vista literario como político: una obra apreciada por su belleza lírica, así como por la brutalidad del mundo que retrata (Waldhorn, 1972, p. 115). Cuando Hemingway publicó la novela logró la admiración de la crítica, el éxito del público y despertar un enorme recelo político en Italia, el país en donde se desarrolla la mayor parte de la obra. En efecto, el personaje principal es un desertor, Frederic Henry, que abandona el ejército italiano y huye a Suiza con su amada, la enfermera Catherine Berkeley.

La deserción de Frederic se produce en uno de los momentos más complejos de la historia militar de ese país: el desastre de Caporetto, una pequeña localidad de los Alpes Julianos. Durante la ofensiva del ejército austro-alemán, que tuvo lugar el 8 de noviembre de 1917 en el frente del Isonzo, el ejército italiano sufrió la pérdida de 12.000 soldados, a los que se les suman más de 30.000 heridos y 240.000 prisioneros. A estos se les debe añadir unos 350.000 soldados que abandonaron su posición y retrocedieron de manera vehemente y anárquica desde Caporetto hasta el río Piave. A pesar de que Italia terminara ganando la Guerra y que el régimen de Mussolini hiciera de las victorias finales del ejército italiano, como la de Vittorio Veneto, el símbolo de una nación gloriosa que había logrado resurgir de sus cenizas militares, la humillación sufrida por la tropa en Caporetto era un tabú para el régimen (Thompson, 2008, pp. 324-327). Cualquier texto que hiciera mención al desastre militar era automáticamente censurado. No es de extrañar que la novela de Hemingway no se publicara en Italia hasta después de la Segunda Guerra Mundial y que el gobierno de Mussolini ejerciera una presión constante, tanto a nivel nacional como internacional, para impedir la difusión de su obra (Cirino, 2014, pp. 30-35; Fortunati, 2006, pp. 226-227). A principios de los años treinta, cuando los estudios Paramount compran los derechos de la obra de Hemingway, estos eran conscientes de la presión internacional que podría ejercer sobre ellos el gobierno italiano. Mussolini había prohibido en Italia, unos años antes, la proyección de Sin novedad en el frente (All Quiet on the Western Front, Lewis Milestone, 1930) debido a su contenido pacifista, aunque el Duce admirase el valor cinematográfico de la película (Kelly, 1999, p. 131). Adiós a las armas, que mostraba con toda crudeza el lado más oscuro de una guerra que para el régimen había sido gloriosa, representaba para el régimen fascista un desafío ideológico aún mayor que el de la película de Milestone. Ante las protestas de la embajada italiana en Nueva York, Paramount distribuyó la película en todo el mundo, menos en Italia, evitando mencionar en ella el nombre de Caporetto, lo que significaba una traición ideológica al texto de Hemingway.

En 1957, Selznick trata de ser fiel a sus principios, se afana por adaptar la novela de Hemingway manteniendo parte de la esencia ideológica de la misma: la representación del desastre de Caporetto. Sin embargo, a pesar de que habían pasado muchos años tras la Gran Guerra, Caporetto seguía siendo uno de los aspectos más oscuros y complejos de la historia de Italia. A partir de 1945, gran parte de la izquierda italiana comenzó a analizar Caporetto no tanto como un mero desastre militar, sino como una rebelión popular en la que el pueblo se alzó realmente con el poder desobedeciendo a sus líderes políticos (De Simone, 1995, p. 46). La deserción en masa fue en realidad una huelga en gran escala que estuvo a punto de acabar para siempre con el poder de la oligarquía militar y burguesa que controlaba el país. Durante la producción de Adiós a las armas en Italia, Selznick es consciente de que el contenido ideológico de la película no va a gustar ni a la izquierda ni a la derecha italianas, que aún consideran la Gran Guerra como un momento histórico glorioso. El plan Marshall, la entrada de Italia en la OTAN y la consolidación política de la Democracia Cristiana habían alejado gradualmente del país trasalpino la posibilidad de un gobierno comunista con el que habían soñado tantos partisanos al terminar la guerra. Sin embargo, las controversias políticas e ideológicas entre la derecha y la izquierda estaban a la 
orden del día en Italia y el cine era el reflejo de esa tensión política que Selznick no podía ignorar. Otras adaptaciones cinematográficas con un gran presupuesto, como Senso (Luchino Visconti, 1954), en la que se ofrecía una interpretación gramsciana del Risorgimento y que proponía una interpretación crítica de otra derrota militar, la de la batalla de Custoza (1866), había provocado la reacción del gobierno italiano, el cual había presionado de manera implacable a los miembros del jurado de la Mostra de Venecia para evitar cualquier reconocimiento internacional de dicha obra de Visconti (Grindon, 1990, pp. 228-230).

Ante la compleja situación política del momento y teniendo en cuenta que el rodaje en Italia de Adiós a las armas se había beneficiado de la ley Andreotti del 20 de febrero de 1949 que autorizaba a las productoras norteamericanas a rodar en Italia sin pagar impuestos, Selznick busca una solución diplomática que le permita contentar al gobierno italiano sin traicionar completamente el texto de Hemingway. Desde el principio de la película se busca que el espectador sepa que va a asistir a un espectáculo cinematográfico, aunque puedan aparecer en la pantalla algunos elementos controvertidos. A pesar de que, al principio, los títulos de crédito aparecen sobreimpresos sobre una imagen de muerte, desolación y ruinas, anunciando que la película tendrá como marco la guerra, enseguida comienzan a aparecer una serie de imágenes que alejan al espectador del horror de la contienda. La Italia pintoresca, aquella que ya había sido retratada en todos sus colores a principios de los años cincuenta en diferentes producciones como las de David Lean o Negulesco, comienza a aparecer delante del espectador: las colinas nevadas de los Alpes, el lago Maggiore, la laguna véneta y la silueta imponente de la catedral de Milán.

Selznick crea, de repente, un texto independiente, lleno de una intensa belleza paisajística con el que se invita al espectador a disfrutar de las montañas y colinas de Italia como un espectáculo visual. El productor parece querer señalar que el horror de la Primera Guerra y su significado político deben ocupar un segundo plano. El espectador va a disfrutar de una Italia íntima y llena de colorido durante la proyección de la película. Tras la presentación de una serie de paisajes, aparece en la pantalla un texto introductorio que se superpone sobre la imagen de una cima montañosa. El texto sirve para codificar ideológicamente la película. En él se aclara que la historia está ambientada en Italia durante la Primera Guerra Mundial, una contienda en la que los italianos lucharon heroicamente (valiantly) y las derrotas fueron tan solo pasajeras, ya que el ejército supo recuperarse con valor (gallantry) hasta alcanzar la victoria final. Por lo tanto, aunque pueda aparecer en la película el desastre de Caporetto, se le anticipa al espectador que se trata tan solo de un hecho pasajero dentro de los avatares de la Primera Guerra. Se insiste en que la película excluye cualquier interpretación del hecho como símbolo de derrotismo o cobardía por parte del ejército italiano. Además, tras esta aclaración, se informa a los espectadores de que lo que van a ver no se trata únicamente de una película de guerra, sino de una historia de amor.

Con tal inicio, Selznick se aparta ideológicamente de Hemingway y logra evitar que la película pueda ser considerada por una parte de la crítica como una defensa de la interpretación de la Guerra defendida por la izquierda italiana. Para ello se apropia de muchos elementos que ya aparecían al comienzo de la película de Borzage. Como en la versión de 1957, la obra de Borzage comienza con una nota aclaratoria en la que se especifica el contenido ideológico de la película. El texto se superpone sobre un cielo cubierto de nubes, en el que antes de la nota había aparecido la presencia amenazadora de la aviación. En la nota se aclara al espectador que todas las naciones han sufrido enormes derrotas durante la Primera Guerra Mundial, pero a pesar de eso, la contienda será recordada por dos grandes victorias, el Marne y el Piave. Claramente, la alusión a la victoria del Piave rinde homenaje a la Italia de Mussolini, tan admirada por una parte de las clases medias norteamericanas en ese momento y por 
muchos productores de Hollywood como, por ejemplo, Hal Roach (Doherty, 2013, pp. 124-127; Gabaccia, 2000, pp. 129-130; Urwand, 2013, p. 175). La alusión a la victoria oscurece las consecuencias políticas y militares que se derivan del desastre de Caporetto para los personajes de la novela de Hemingway. Esta nota aclaratoria sirve, también, para proteger los intereses de la Paramount en Italia. Aunque el régimen de Mussolini prohibiera en su país la película, ciertamente la distribución internacional de la película, en la que se atacaba directamente a los símbolos del poder fascista, podría acarrear graves consecuencias para la productora.

A continuación, tras esta aclaración ideológica, Borzage se recrea con la belleza del pasaje bucólico de los Alpes italianos. Con una gran delicadeza, muestra la armonía de lo humano y la naturaleza: las montañas y los valles que invitan a la paz, a la contemplación y al descanso. Es una escena digna de Tiziano o de Giorgione que evoca un universo de placidez y de sensualidad. Sin embargo, pronto el paisaje idílico del norte de Italia se transforma en algo diferente, de manera amenazadora. De repente, la cámara muestra la figura de un soldado, dormido sobre la hierba de una ladera, pero que se trata en realidad de un cadáver (Belton, 1974, p. 87). A continuación, aparecen en el fondo del paisaje una serie de ambulancias de la Cruz Roja que avanzan con dificultad por las laderas de las montañas. Estos vehículos son el símbolo de la guerra y del fin de la civilización que supone el conflicto bélico.

Antes de pasar a mostrar la historia de amor que surge entre Frederic (Gary Cooper) y Catherine (Helen Hayes), Borzage quiere que el espectador se dé cuenta de que la guerra va a suponer el fin de un orden que va a afectar tanto a la vida de los personajes como al paisaje del norte de Italia. Con este inicio, Borzage logra armonizar las presiones internacionales, a las que se vio sometida la producción de la película, con la ideología pacifista que articula el texto de Hemingway. Las imágenes van más allá de las palabras celebrando el heroísmo de la contienda. Es como si Borzage quisiera decirnos que la Gran Guerra no ha sido simplemente un acontecimiento bélico más, que ha sido el fin de una civilización y que ya nada volverá a ser igual que antes. Selznick, por el contrario, nos ofrece una extraña mezcla de guía turística y de espectáculo militar. La serie de imágenes que acompañan a los títulos de crédito de la película son el reflejo de las contradicciones y las dudas del productor que es incapaz de enfrentarse a las consecuencias ideológicas del texto de Hemingway.

\section{LA ESTRATEGIA MELODRAMÁTICA}

En su adaptación de la obra de Hemingway, Selznick recurre a una estrategia melodramática orientada a atraer a las salas a un espectador femenino que Hollywood quiere recuperar tras la severa crisis que ha sufrido la industria después de la Segunda Guerra Mundial (Barlowe, 2011, pp. 34-35). Además, la interpretación melodramática se corresponde con la propia lectura que ha hecho el productor de la novela. Para Selznick, la Gran Guerra es tan solo un mero background, en el que se desarrolla una trágica historia de amor (Selznick, 2000, p. 483). La defensa de una lectura melodramática de la novela provocó un intenso enfrentamiento al comienzo del rodaje entre Selznick y John Huston. Huston defendía una interpretación diferente del texto, en la que el escenario bélico resulta fundamental para comprender a los personajes. Como fruto de la tensión entre el director y el productor, Huston decidió abandonar el rodaje y Selznick se vio obligado a contratar a Charles Vidor (Huston, 1980, p. 273). La relación entre Vidor y Selznick resultó también extremadamente tensa debido a que los dos diferían en cuanto a la interpretación del texto. Vidor quiso apartarse de la novela de Hemingway, lo que no agradó a Selznick. El difícil equilibrio entre cine y literatura que busca el director norteamericano no logra satisfacer a ninguno de sus colaboradores (Selznick, 2000, pp. 482-485).

Selznick elige a una pareja de actores como protagonistas: a su mujer, Jennifer Jones (Catherine), y a Rock Hudson (Frederic). En los años cincuenta ambos actores habían aparecido en diferentes 
melodramas que habían gozado de un gran éxito en taquilla. Unos años antes, Jennifer Jones había sido protagonista de La colina del adiós (Love is a Many-Splendored Thing, Henry King, 1955), uno de los grandes melodramas de la década. Rock Hudson se había convertido en una estrella protagonizando una serie de melodramas dirigidos por Douglas Sirk ambientados en pequeñas localidades de los Estados Unidos: Obsesión (Magnificent Obsession, 1954) y Sólo el cielo lo sabe (All that Heaven Allows, 1955). La elección de los actores favorecía el que los espectadores identificaran, antes de acudir a la sala, a Adiós a las armas con el melodrama de los años cincuenta. Además, entre Jennifer Jones y Rock Hudson existía una diferencia de edad de cinco años. En la novela de Hemingway en ningún pasaje aparece que Catherine pudiera ser mayor que Frederic. Como veremos a continuación, la edad de Jennifer Jones va a condicionar la construcción melodramática del remake.

Pero, antes de fijarnos en los detalles de la construcción melodramática, sería oportuno señalar que, aunque Selznick pretenda ser más fiel a la novela de Hemingway que Borzage, lo cierto es que la estructura dramática del remake se apoya en la de la versión de 1932 (Selznick, 2000, pp. 490-491). Como Frank Borzage, Selznick reconoce que utiliza como fuente, no solo la novela de Hemingway, sino también la primera adaptación teatral de la misma realizada por Laurence Stallings en 1930. A partir del trabajo de Stallings, Borzage recreó un melodrama en el que los personajes principales, Frederic y Catherine, renuncian a la guerra y escapan del frente, tras descubrir que hay algo más importante que las banderas y los nacionalismos: el amor. Es la fuerza del amor, su deseo por reunirse con Catherine, lo que hace que el personaje interpretado por Gary Cooper decida abandonar el frente y buscar a la amada en un momento en que las tropas italianas han conocido la victoria tras conquistar San Daniele. El personaje que aparece en la película de Borzage se aparta de manera radical del Frederic que aparece en la novela de Hemingway que decide desertar después del desastre de Caporetto.

Como Borzage, Selznick opta por crear una estructura narrativa en la que los personajes principales se alejan no solo física sino también mentalmente de la guerra. El amor se convierte gradualmente en el centro del relato. En los momentos finales de la película, cuando Frederic y Catherine planean cruzar el Lago Maggiore y escapar a Suiza, la pareja aparece completamente separada del contexto bélico. Indiferentes al mundo, alojados en un lujoso hotel, parecen una pareja de turistas norteamericanos que se encuentran de vacaciones en Italia. En la versión de Borzage, el personaje interpretado por Gary Cooper logra escapar a Suiza con la ayuda de sus amigos italianos. No es ni mucho menos un personaje aislado y separado del resto de la población como lo son los personajes de la versión de 1957.

Selznick, al elegir a Rock Hudson como actor principal, construye una historia de amor entre un hombre joven y una mujer madura, un tipo de historia que se asemeja mucho a los melodramas dirigidos por Douglas Sirk en esa década, en los que dicho actor aparece en compañía de una mujer más madura, interpretada por Jane Wyman. En ese modelo melodramático la diferencia de edad entre el hombre y la mujer produce una enorme tensión dramática. La pareja tiene que enfrentarse a un contexto social e institucional que no tolera dicha relación. La elección de Jennifer Jones y Rock Hudson transforma la historia amorosa de manera parecida a la de los melodramas de Sirk, en los que se produce un aislamiento gradual de la pareja en un entorno que se vuelve hostil.

La construcción melodramática de Selznick, aunque tiene como referencia la de Borzage, se va alejando de la primera adaptación. En la obra de Borzage, Frederic es un soldado veterano que ha conocido el horror de la Guerra. Catherine simboliza, por el contrario, la inocencia y la juventud, a pesar de que ha conocido un pasado trágico, ya que su prometido ha muerto en el frente de Francia. Es esa inocencia la que hace que Frederic se regenere internamente y encuentre un motivo transcendente que le haga renunciar a las armas y arriesgar su vida. Como ha señalado Patrick Keating, la foto- 
grafía de Lang tiende a contrastar la masculinidad de Gary Cooper con la inocencia de Helen Hayes, que aparece retratada en muchos fotogramas como un rostro plano, sin sombras ni arrugas, símbolo de intimidad y pureza (Keating, 2010, pp. 175-176). La imagen de Helen Hayes en la obra de Borzage contrasta con la imagen de Jennifer Jones en la versión de Selznick. La inocencia trágica de Catherine desaparece por completo en la versión de Selznick. Los primeros planos muestran a menudo el rostro cansado y arrugado de la actriz que contrasta con la juventud del personaje interpretado por Rock Hudson que se aleja por completo de la madurez y masculinidad de Gary Cooper en la versión de 1932. La elección de Hudson trasmite al personaje de Frederic una cierta inocencia muy lejana de la de un oficial de la Cruz Roja que ha vivido intensamente dos años de combate en el frente. No es de extrañar que cuando John Huston le pide al productor que le corten el pelo a Rock Hudson para parecer realmente un oficial italiano de la época, Selznick se niegue a hacerlo (Huston, 1980, p. 271). Quiere que el personaje de Frederic retenga la frescura y el desenfado de los personajes que ha interpretado Hudson anteriormente.

Selznick trata de resolver el problema de la diferencia de edad entre Jennifer Jones y Rock Hudson alterando ciertos aspectos de la novela. El personaje interpretado por Jennifer Jones aparece al comienzo de la película como un ser trágico, hermoso y misterioso que identifica a la lluvia con la muerte. En cambio, el personaje de la novela va descubriendo progresivamente que su vida tiene un cierto destino trágico. Selznick trata que la audiencia identifique a Jennifer Jones con otros personajes trágicos que había interpretado anteriormente, como en La canción de Bernardette (The Song of Bernardette, Henry King, 1943) o Jennie (Portrait of Jennie, William Dieterle, 1949). Son personajes misteriosos, vinculados a un destino trágico y que son conscientes de antemano del mismo. El personaje interpretado por Rock Hudson se deja seducir por ese ser misterioso y participa de su tragedia, aunque hay siempre una cierta distancia que separa a los personajes, nunca llegan al grado de unión que muestra la pareja de enamorados de Borzage. Es como si Selznick quisiera focalizar la tensión dramática de la novela exclusivamente en el personaje de Catherine.

La Catherine interpretada por Helen Hayes era también un personaje atrapado por el destino, pero de una manera diferente al personaje interpretado por Jennifer Jones. En la versión de Borzage, Catherine aparece como una mujer romántica atrapada por las circunstancias de la Guerra, en las que todo es excepcional. Es un universo constantemente cambiante, en el que las cosas tienen que hacerse deprisa, ya que la amenaza de la muerte está siempre presente, y este hecho trasforma de manera radical las relaciones humanas. Con el fin de evitar la censura, debido a que el amor entre Catherine y Frederic es completamente ilícito para la moral de la época, se insiste en que en circunstancias diferentes Catherine hubiese actuado de otra forma: no se hubiese quedado embarazada sin antes haberse casado. La película se produce en un momento histórico en el que Hollywood comienza a ser controlado por los grupos más reaccionarios de la sociedad norteamericana (Rubin, 2007, p. 95). No es de extrañar que el personaje interpretado por Helen Hayes se trate, en el fondo, de una mujer como tantas otras que deben enfrentarse a la guerra que las obliga a tomar decisiones extremas. En ningún caso se trata de un ser trágico y misterioso como el encarnado por Jennifer Jones, tal y como aparece en la película de Selznick.

Como podemos apreciar, los condicionamientos relacionados con la producción afectan de manera directa al contenido y a la ideología del remake que probablemente hubiese sido muy diferente sin la presencia de Jennifer Jones. 


\section{HiSTORIA, IDEOLOGÍA Y CAPORETTO}

A pesar de recurrir a una estrategia melodramática a la hora de adaptar a la pantalla Adiós a las armas, Selznick no renuncia por completo a ser fiel al texto de Hemingway. Al contrario que en la versión de 1932, en 1957 se menciona explícitamente la localidad de Caporetto, un lugar fatídico en la historia de Italia. Sin embargo, Selznick sigue de cerca la adaptación de Borzage. Ambas obras eliminan episodios de la novela que resultan esenciales para comprender por qué Frederic Henry decide abandonar el ejército italiano tras el desastre militar.

El episodio de la retirada de las tropas italianas de la ciudad de Gorizia y la progresiva marcha hacia el río Piave huyendo de la invasión austro-alemana representa uno de los acontecimientos más intensos de la novela de Hemingway. Acompañado de tres soldados de la Cruz Roja (Aymo, Bonello y Piani), Frederic Henry recibe la orden de abandonar su posición en Gorizia y se une a la retirada masiva del ejército italiano tras el desastre militar de Caporetto. A lo largo de la noche, la ambulancia en la que va Frederic es incapaz de avanzar debido a la enorme cantidad de militares y de civiles que se van uniendo a la retirada. Ante la posibilidad de avanzar, Frederic y sus tropas deciden desviarse de la carretera principal y salir por la carretera de Cormons hacia Udine. El desvío se trasforma en una pesadilla para Frederic y sus hombres. Alejados de la carretera principal y del control del ejército, el grupo se enfrenta a la brutalidad de una guerra en la que el enemigo ya no es el ejército austro-alemán, sino los propios soldados italianos. Tratando de mantener el orden y la disciplina, Frederic se ve obligado a matar a un soldado italiano que se niega a seguir las órdenes de sus superiores. Bonello deserta del grupo tras haber rematado en el suelo con una pistola a un oficial italiano. Aymo muere en los alrededores de Udine víctima de los disparos de los soldados de su propio ejército. Antes de volver a la carretera principal que lo llevará al río Tagliamento, Frederic ha comprobado el horror y el caos de una retirada en la que los altos oficiales del ejército italiano han desaparecido y abandonado a las tropas a su suerte. El texto de Hemingway muestra el paisaje después de la batalla como el de una guerra civil anticipada entre la izquierda italiana y las clases altas, representadas por los oficiales. Es una imagen que no tiene nada que ver con la idea de la Primera Guerra Mundial como prueba de la unidad nacional defendida por el Fascismo y nos ayuda a comprender por qué para el régimen era tan peligrosa la adaptación cinematográfica de la novela de Hemingway.

Selznick quiere mostrar el caos de Caporetto, la tragedia colectiva que sacude no solo a los militares, sino también a toda la población civil (Bultrini \& Tentori, 2008, p. 112). Sin embargo, el productor renuncia a sacar a la luz la compleja ideología que se encuentra en la novela de Hemingway. Transforma la humillación nacional sufrida por las tropas italianas tras la invasión austro-alemana, en la tragedia personal del oficial Rinaldi (Vittorio De Sica) que acompaña a Frederic en la retirada. Rinaldi es un médico patriota que no quiere abandonar a sus enfermos en el hospital de Gorizia. Rinaldi está enfermo de sífilis, lo que sirve para acentuar su rabia y su desprecio personal. Sin embargo, tiene que acatar las órdenes del Alto Mando y se une a Frederic, Aymo y Bonello. Los personajes montan en una ambulancia y se retiran por la carretera con el resto de las tropas y civiles hacía el río Tagliamento. En ningún momento los personajes se alejan de la carretera principal. La retirada aparece retratada como un enorme desastre humano. Los militares, las mujeres, los viejos y los niños avanzan por carreteras embarradas con rostros derrotados. El cansancio se apodera de todos. Después de que Bonello se separara del grupo para ayudar a una madre incapaz de avanzar por el lodo con su hijo en brazos, el oficial de la Cruz Roja no puede volver a reunirse con el grupo. Se enzarza en una pelea con un civil que quiere impedir que la mujer y el niño suban a la ambulancia y, tras acabar con el hombre, Bonello ya no puede continuar adelante y permanece tendido a un lado del camino. La fatiga se apodera también de la mujer que es incapaz de sujetar al niño entre los brazos y lo pierde. Son escenas en las que 
se muestra el efecto de la guerra en la población civil y en el ejército. La guerra moderna significa la guerra total en la que los primeros en ser sacrificados son los inocentes, una idea que Hemingway expresa en muchos de sus relatos (Pozorski, 2004). Ciertamente, la adaptación de Selznick muestra el efecto de la invasión austro-alemana, pero ignora por completo el significado político de la derrota de Caporetto. Una derrota en la que millares de soldados tiraron las armas y decidieron poner fin a la Primera Guerra Mundial, rebelándose al poder tiránico de una clase alta militar que había decido enviarles a la muerte y que había traicionado a la población civil al ser los primeros en retirarse del campo de batalla hacia el Piave tras el desastre militar.

En ese sentido la adaptación de Selznick sigue fielmente muchos elementos que aparecen en la película de Borzage, en la que se describe la retirada como un momento apocalíptico de la humanidad. Las escenas habían sido rodadas por la segunda unidad bajo la dirección de Jean Negulesco. El director rumano ideó un montaje experimental para mostrar los efectos del desastre en que se alternan las imágenes de los civiles y los soldados que huyen en retirada con una avalancha de agua que va engullendo a los árboles, las casas y las paredes de las ciudades incendiadas por los bombardeos (Negulesco, 1984, p. 96). La retirada se transforma en un espectáculo colosal en el que la guerra se muestra como algo sobrehumano que destruye a los soldados, a la población civil, a los animales, los cementerios y la naturaleza. Es una imagen precursora de El Guernica de Picasso que pudo haber visto la película de Borzage (De Pablo, 2011, p. 58). En la versión de 1957, la representación de la guerra no tiene el poder metafísico que aparece en la obra de Borzage ni las implicaciones políticas, recordemos que el Fascismo se sintió atacado directamente por la versión de 1932. Sin embargo, de manera fragmentaria, la versión de 1957 logra mostrar lo que supone para una población civil un nuevo tipo de guerra que ya nada tiene que ver con el de las guerras del siglo XIX.

La versión de Selznick trata de intensificar la descripción del absurdo y el horror de la guerra mostrando uno de los episodios más complejos de la novela de Hemingway: los fusilamientos sumarios de oficiales italianos que tienen lugar en las orillas del río Tagliamento que van a forzar a Frederic Henry a desertar del ejército. La versión de 1957 muestra cómo Frederic en compañía de Rinaldi y de Aymo se acerca al río Tagliamento y allí se encuentra con un paisaje desolador y macabro: mujeres muertas en el fango, un espía alemán que cuelga de una alambrada, y un sinfín de utensilios y material militar dispersos por la carretera. Ante esa sensación de desolación y desesperación, Rinaldi se siente humillado y expresa verbalmente su decepción. Al oír sus quejas, los carabinieri, que en ese momento custodian el puente que atraviesa el río, lo confunden con un espía alemán y detienen al oficial italiano. Frederic acompaña a Rinaldi. Un histriónico Rinaldi se defiende torpemente ante sus superiores. Confuso y enfermo tras la larga y angustiosa retirada, Rinaldi es incapaz de aclarar si es un espía alemán o un desertor. El tribunal lo condena a muerte. Mientras un pelotón se dispone a ejecutar a Rinaldi, Frederic trata de defender a su amigo, pero lo único que consigue es que el tribunal piense que él también sea un espía alemán. Cuando Frederic se da cuenta de que todo es inútil, que han ejecutado a Rinaldi y que le espera el mismo destino, se escabulle en un descuido del ejército y logra arrojarse al río, lo que propicia su huida y el comienzo de su adiós a las armas.

La elección de Vittorio De Sica en el papel de Rinaldi logra transmitir el absurdo de la guerra. De Sica había interpretado por aquel entonces a un noble decadente, poseído por el juego, que aún retenía una cierta dignidad en un episodio de El oro de Nápoles (L'oro di Napoli, De Sica, 1954) que había acrecentado su fama internacional como actor. Su destino trágico en Adiós a las armas simbolizaba las contradicciones del poder militar que acababan con la vida de un patriota. En la versión de Borzage la escena de los fusilamientos acontecidos en la orilla del Tagliamento mostraba las ejecuciones y la huida de Frederic de una manera veloz y confusa. Todo el episodio relacionado con la retirada de Caporetto 
era en realidad poco claro (Ghigi, 2014, p. 229). Además, el diálogo entre Frederic y el tribunal militar había sido eliminado, lo que impedía al espectador que no hubiese leído la novela de Hemingway entender lo que estaba pasando. Claramente, los estudios Paramount no podían prescindir de esa escena de la novela, pero al mismo tiempo no podían mostrar explícitamente el contenido político de la misma, ya que no habría gustado al régimen de Mussolini. La preocupación por los efectos políticos de la película se podía ya apreciar en las escenas iniciales en las que Bonello, que aparece definido explícitamente como socialista en el guion original de Benjamin Glazer y Oliver H. P. Garrett, aparece retratado, en la versión final, como un soldado apolítico que se encuentra disconforme con sus superiores (Glazer \& Garrett, 1932, p. 7). El contenido antifascista de la obra se manifiesta a través del simbolismo estético y no a través de los diálogos.

La versión de 1957, aunque incluye una parte del enfrentamiento dialéctico entre Frederic y los militares italianos, altera de forma radical el sentido del texto de Hemingway. En primer lugar, como hemos mencionado anteriormente, focaliza la acción en la tragedia personal del mayor Rinaldi, un personaje que desaparece de la novela de Hemingway justo antes del desastre de Caporetto. En segundo lugar, el patriotismo de Rinaldi enmascara la rebeldía ante una guerra inútil. La futilidad de la contienda se refleja en la novela cuando Frederic, el narrador, describe cómo las tropas italianas, según se van aproximando al río Tagliamento, jarrojan sus fusiles y gritan «a basso gli ufficiali!» (sic) (Hemingway, 1995, p. 219). Finalmente, al mostrar a Rinaldi como un oficial enfermo que se defiende torpemente ante un consejo de guerra y cuya trágica muerte es por lo tanto el producto de una serie de circunstancias adversas, se desvirtúa el alcance ideológico que tiene este episodio en la obra de Hemingway.

En la novela de Hemingway los fusilamientos de altos cargos del ejército que tienen lugar tras la retirada de Caporetto muestran la profunda división de la sociedad italiana durante la Gran Guerra y que se va a cristalizar con la llegada al poder del Fascismo. En la novela los oficiales fusilados simbolizan a una generación de valientes soldados italianos atrapados por la negligencia de los altos mandos militares. Aquellos que los ejecutan, los carabinieri, representan la burocracia y la cobardía, aquellos que nunca han tenido el valor de luchar en el frente, aquellos que se ocultan en la retaguardia, y que se aprovechan de una serie de circunstancias favorables para eliminar a una generación destrozada por la guerra. Los carabinieri encarnan el poder que va a surgir tras el Fascismo y, para Hemingway, Mussolini no era más que un falso héroe de la retaguardia, al que Hemingway había entrevistado después de la guerra (Hemingway, 1985, pp. 253-256). No hay que olvidar que Adiós a las armas es una novela escrita por un hombre que se unió al ejército italiano como oficial de la Cruz Roja durante la Primera Guerra Mundial y sirvió en ella con entusiasmo hasta el punto de interiorizar profundamente la cultura italiana (Cecchin, 1980, pp. 198-205; Reynolds, 1976, pp. 14-18). Sin embargo, con la llegada del Fascismo y, especialmente, tras el asesinato en 1924 del líder socialista Giacomo Matteotti, el escritor se desencanta completamente del país trasalpino (Hemingway, 2013, pp. 386-387; Ott, 2005, pp. 18-21). Por lo tanto, aunque se trate de una historia de amor con ciertos elementos autobiográficos, la novela de Hemingway es inseparable de la política, algo que Selznick se resiste a aceptar.

El proceso de deshistorización de la novela de Hemingway se pone de manifiesto al final de la película de Selznick. Tras escapar del pelotón de fusilamiento, Frederic logra reunirse con Catherine en Stresa. Perseguido por las autoridades italianas al ser considerado como un desertor, consigue apoderarse de una barca y en compañía de Catherine logra atravesar el Lago Maggiore y llegar a Suiza. Con dinero suficiente para vivir holgadamente, la pareja se refugia en un hotel al lado de los Alpes. Indiferente a la guerra, Frederic se siente feliz, del todo ajeno al destino de sus compañeros de armas. Solo abandona la idílica localidad cuando acompaña a Catherine, que está a punto de dar a luz, a un hospital 
de Lausana. Allí, tras saber que su mujer ha perdido el hijo que esperaba y que esta se siente muy débil, abandona por unos momentos el hospital para ir a un café local, donde nada más entrar, Frederic vuelve a tomar contacto con la guerra, pues allí la gente lee los periódicos y comenta en voz alta que las tropas italianas han logrado defender la línea del río Piave y que el éxito italiano ha sido reconocido por los propios enemigos. En la novela de Hemingway cuando Frederic entra en el café, no se hace ninguna mención a la vitoria de las tropas italianas, tan solo se habla del éxito del ejército francés que comienza a recuperar posiciones en el frente occidental. En la película de Borzage, Frederic recibía la noticia, antes de entrar al café, de que la guerra había terminado y que las tropas italianas habían resultado victoriosas. Tanto la película de Borzage como la de Selznick tratan de oscurecer el pesimismo de Hemingway y enfatizar que Caporetto representa un episodio aislado defendiendo una imagen victoriosa de Italia cercana a la interpretación fascista que va a crear el mito de la Gran Guerra y silenciar los aspectos más oscuros de la contienda (Rochat, 2006, p. 320).

\section{TRANSCENDIENDO EL EXISTENCIALISMO}

En los momentos finales de la película, cuando Frederic asiste en el hospital a la muerte de su amada debido a una hemorragia tras el parto, la versión de 1957 trata de ser fiel al texto de Hemingway y reproduce gran parte de los diálogos que tienen lugar en el hospital entre Catherine y Frederic. En ellos se muestra cómo los dos personajes se enfrentan con una gran valentía y coraje al horror al que les ha conducido la fuerza de las circunstancias. El pesimismo existencial de la novela de Hemingway emerge especialmente en los diálogos y en los soliloquios de Frederic. Sus palabras van más allá del mero melodrama de los años cincuenta y muestran la cara oculta del sueño americano. La muerte de Catherine le hace ver a Frederic que el valor y el coraje son inútiles, que la vida es injusta, y que aquellos que sobreviven no son siempre los mejores. Su pesimismo contrasta con la creencia en el progreso ilimitado que forma parte no solo de la ideología de Hollywood, sino también de una parte importante de la cultura estadounidense. Así lo revelan, por ejemplo, los estudios sociológicos de Karen Cerulo (1995). La versión de 1957 de Adiós a las armas no oculta el pesimismo existencial de Frederic que, ante la muerte inminente de su amada, descubre que en la vida muchas veces no hay segundas oportunidades, que, aunque el error forme parte del aprendizaje, en ocasiones hay errores que son irreversibles, que al placer le sigue el dolor y que la naturaleza nos atrapa a todos, tarde o temprano.

El existencialismo de Hemingway pone en duda la libertad de los seres humanos y muestra la naturaleza como una fuerza ciega e indiferente a lo humano. En la desierta habitación del hospital, el personaje interpretado por Rock Hudson mira al vacío de lo humano encarnado en el rostro lleno de dolor y sufrimiento de Catherine. La puesta en escena de Vidor muestra a Catherine extendida sobre el blanquecino lecho como si fuese una estatua. Es una imagen que tiene la belleza de El Cristo muerto (Cristo morto, ca. 1475-78) de Mantegna, una de las mayores influencias pictóricas en Hemingway (Watts, 1971, p. 135). Ese pesimismo existencial, que se origina en el momento que Catherine da a luz y pierde a su hijo, había sido evitado en la versión de Borzage. En la versión de 1932, la muerte de Catherine no significa el fin del amor. El personaje interpretado por Gary Cooper eleva elegantemente el cadáver de Catherine envuelto en las sábanas de la cama y se dirige a la ventana iluminado por una luz blanquecina, mientras afuera se oyen gritos de júbilo y alegría, ya que la guerra ha terminado. Para Borzage el amor va más allá de la vida, conocerlo es una experiencia sublime que cambia para siempre a los seres humanos (Dumont, 2006, pp. 186-187). El final de Adiós a las armas expresa la fe en el amor con la misma intensidad que el de otra de sus grandes obras, El séptimo cielo (7th Heaven, 1927). Además, en una época en la que comienza a vislumbrarse el poder de los totalitarismos con la invasión de Libia 
por parte de las tropas de Mussolini en 1932, la defensa a ultranza del valor de la paz supone todo un reto para aquellos que identifican la violencia con el progreso. Traicionando al texto de Hemingway, Borzage logra comunicar una ideología no menos revolucionaria y controvertida que la de la novela.

En la versión de 1957, a pesar de la puesta en escena realista y existencial de Vidor, Selznick recurre también a un final transcendental con el fin de que la audiencia no se deje contagiar por el pesimismo de Hemingway. Cuando Frederic abandona en silencio el hospital tras ver cómo su amada se ha convertido en una estatua, una música melódica invade la escena y, a continuación, aparece la imagen de Catherine que le recuerda a Frederic que ella ha elegido ese tipo de vida y ese final trágico. Es un final truculento que contrasta con el final de Borzage, el cual, en definitiva, forma parte de la estética del director de origen italiano. Se desvanece de repente todo el horror de la novela de Hemingway. La música melódica y la superposición de una voz o una imagen que evocan el recuerdo de un ser amado muerto acompañando a una figura solitaria nos hace recordar a otros melodramas de la época, como el final de La colina del adiós. Selznick es otra vez incapaz de llevar hasta las últimas consecuencias la obra que pretende adaptar fielmente y que espera que Hemingway aprecie. El resultado final de la versión de 1957 es un texto complejo y de muchas lecturas que es también el reflejo de las contradicciones y ambiciones desproporcionadas del productor. En 1957, el año en que se estrenan dos obras políticamente valientes y ambiciosas con un contenido pacifista como El puente sobre el río Kwai (The Bridge on the River Kwai, David Lean) y Senderos de gloria (Paths of Glory, Stanley Kubrick), a partir de las novelas homónimas de Pierre Boulle y de Humphrey Cobb, Selznick se enfrenta también a un texto polémico como la novela de Hemingway y ofrece una interpretación muy personal de la misma.

\section{CONCLUSIONES}

La adaptación producida por Selznick de Adiós a las armas de Hemingway es un paradigma de un tipo de remake que se origina a partir de un deseo del productor por emular y superar, al mismo tiempo, una versión anterior, la del 1932. Aunque Selznick trata de legitimar el valor del remake al intentar ser más fiel a la novela que la versión anterior, lo cierto es que no consigue su objetivo y, como hemos visto, en muchos aspectos la versión de Borzage está más cerca del espíritu pacifista de la obra de Hemingway que la de 1957.

El fracaso de taquilla que obtuvo la película de Selznick nos muestra lo complejo que supone acercarse a un texto clave de la literatura del siglo XX, tanto por su valor literario como político, y tratar de adaptarlo a una cultura de masas. La adaptación de Selznick ya partía de una lectura muy parcial de la obra de Hemingway, al tratar de abstraer una historia de amor que estaba intrínsecamente unida a la Primera Guerra Mundial. La focalización en la historia de amor le llevará a una progresiva deshistorización de muchos elementos relacionados con el frente italiano durante la guerra y, especialmente, a ofrecer una visión fragmentaria del texto de Hemingway que no ayuda a comprender los motivos que llevan al personaje principal, Frederic Henry, a desertar del ejército y a desinteresarse por la suerte de sus compañeros de armas.

Pero, sobre todo, la versión de 1957 muestra el poder de Hollywood a la hora de controlar la Historia, de manipular los acontecimientos del pasado, colonizar la memoria y mostrarse incapaz, en ese momento, los años cincuenta, en plena Guerra Fría, de abrirse a otras culturas que no sean la norteamericana. A pesar de estar rodada en Italia y de mostrar la belleza de los escenarios naturales de ese país, la versión de Selznick es un ejemplo de la autarquía cultural de los Estados Unidos en ese periodo, al pretender que un episodio tan fundamental para la historia de Italia como la Grande Guerra no sea más que el mero background de una historia de amor. En efecto, la versión de Borzage, aunque 
rodada enteramente en Hollywood, muestra un mayor número de elementos culturales y lingüísticos de la cultura italiana que la versión de Selznick.

El estudio comparado del remake de Adiós a las armas realizado en 1957 con la versión de 1932 constituye, por lo tanto, un importante instrumento para comprender los cambios y las trasformaciones culturales que ha experimentado la relación entre los Estados Unidos y Europa tras la Segunda Guerra Mundial.

\section{BIBLIOGRAFÍA}

Barlowe, J. (2011). «They Have Rewritten It All»: Film Adaptations of A Farewell to Arms. The Hemingway Review, 31(1), 24-42.

Belton, J. (1974). The Hollywood Professionals: Howard Hawks, Frank Borzage, Edgar G. Ulmer. London: The Tantivy Press.

Bultrini, N., \& Tentori, A. (2008). Il cinema della Grande Guerra. Chiari (Brescia): Nordpress Edizioni.

Cecchin, G. (1980). Con Hemingway e Dos Passos sui campi di battaglia italiani della Grande Guerra. Milano: Mursia.

Cerulo, K. A. (1995). Identity Designs: The Sights and Sounds of a Nation. New Brunswick, NJ: Rutgers University Press.

Cirino, M. (2014). The Nasty Mess: Hemingway, Italian Fascism, and the New Review Controversy of 1932. The Hemingway Review, 33(2), 30-47.

Corkin, S. (1989). Hemingway, Film, and U.S. Culture: In Our Time and The Birth of a Nation. En C. M. Oliver (Ed.), A Moving Picture Feast: The Filmgoer's Hemingway (pp. 148-161). New York, NY: Praeger.

De Pablo, A. (2011). El Guernica, Adiós a las armas, Las Meninas y Alcaine. Cameraman. Revista técnica cinematográfica, 52, 52-61.

De Simone, C. (1995). L'Isonzo mormorava. Fanti e generali a Caporetto. Milano: Mursia.

Doherty, T. (2013). Hollywood and Hitler, 1933-1939. New York, NY: Columbia University Press.

Dumont, H. (2006). Frank Borzage: The Life and Films of a Hollywood Romantic. Jefferson, NC; London: McFarland.

Fortunati, V. (2006). Hemingway, the Embodiment of the American Myth, and Italian Leftist Writers. En R. Sanderson (Ed.), Hemingway's Italy: New Perspectives (pp. 225-231). Baton Rouge, LA: Louisiana State University Press.

Gabaccia, D. R. (2000). Italy's Many Diasporas. Seattle, WA: University of Washington Press.

Ghigi, G. (2014). Le ceneri del passato: Il cinema racconta la Grande Guerra. Soveria Mannelli (Catanzaro): Rubbettino Editore.

Glazer, B., \& Garrett, O. H. P. (1932). A Farewell to Arms: Screenplay; from the Novel by Ernest Hemingway. (Manuscrito).

Grindon, L. (1990). Risorgimento History and Screen Spectacle: Visconti’s Senso. En R. Sklar \& C. Musser (Eds.), Resisting Images: Essays on Cinema and History (pp. 225-250). Philadelphia, PA: Temple University Press.

Grissom, C. U. (2014). Fitzgerald and Hemingway on Film: A Critical Study of the Adaptations, 1924-2013. Jefferson, NC; London: McFarland.

Hecht, B. (1957). A Farewell to Arms: Screenplay. (Manuscrito).

Hemingway, E. (1985). Dateline: Toronto. The Complete Toronto Star Dispatches, 1920-1924. W. White (Ed.). New York, NY: Scribner.

Hemingway, E. (1995) A Farewell to Arms. New York, NY: Simon and Schuster.

(C) Ediciones Universidad de Salamanca / CC BY - NC ND $\quad$ Fonseca, Journal of Communication, n. 14, 2017, pp. 75-89 
Hemingway, E. (2013). The Letters of Ernest Hemingway. Volume 2. 1923-1925. S. Spanier, A. J., De Fazio III, \& R. W. Trogdon (Eds.). Cambridge: Cambridge University Press.

Hotchner, A. E. (2005). Papa Hemingway. A Personal Memoir. Cambridge, MA: Da Capo Press.

Huston, J. (1980). An Open Book. New York, NY: Alfred A. Knopf.

Hutcheon, L. (2006). A Theory of Adaptation. London; New York, NY: Routledge.

Keating, P. (2010). Hollywood Lighting: From the Silent Era to Film Noir. New York, NY: Columbia University Press.

Kelly, A. (1999). All Quiet on the Western Front. The Story of a Film. London; New York, NY: I. B. Tauris. Laurence, F. M. (1982). Hemingway and the Movies. New York, NY: Da Capo Press.

Leff, L. J. (1999). Hemingway and his Conspirators. Hollywood, Scribners, and the Making of America Celebrity Culture. Lanham, MD: Rowman \& Littlefield.

Leitch, T. M. (2002). Twice-Told Tales: Disavowal and the Rhetoric of the Remake. En J. Forrest \& L. R. Koos (Eds.), Dead Ringers: The Remake in Theory and Practice (pp. 37-62). Albany, NY: State University of New York Press.

McElhaney, J. (2003). Frank Borzage: Architect of Ineffable Desires. Senses of Cinema, 25. Recuperado el 17 de marzo de 2017 de http://www.sensesofcinema.com/2003/great-directors/borzage/

Negulesco, J. (1984). Things I Did... and Things I Think I Did. New York, NY: Simon \& Schuster.

Ott, M. P. (2005). Nick Adams at a Windy Cross Roads: Echoes of Past and Future Fictions in Ernest Hemingway's «Che Ti Dice la Patria?». The Hemingway Review, 24(2), 18-27.

Phillips, G. D. (1980). Hemingway and Film. New York, NY: Frederic Ungar.

Pozorski, A. L. (2004). Infantry and Infanticide in A Farewell to Arms. The Hemingway Review, 23(2), 7598.

Reynolds, M. (1976). Hemingway's First War: The Making of a Farewell to Arms. Princeton, NJ: Princeton University Press.

Rochat, G. (2006). L'esercito italiano da Vittorio Veneto a Mussolini, 1919-1925. Bari: Laterza.

Rubin, M. (2007). 1933: Movies and the New Deal in Entertainment. En I. R. Hark (Ed.), American Cinema of the 1930s: Themes and Variations (pp. 92-116). New Brunswick, NJ: Rutgers University Press.

Selznick, D. (2000). Memo from David O. Selznick. Rudy Behlmer (Ed.). New York, NY: Random House.

Thompson, M. (2008). The White War: Life and Death on the Italian Front, 1915-1919. London: Faber and Faber.

Urwand, B. (2013). The Collaboration: Hollywood's Pact with Hitler. Cambridge, MA: The Belknap Press of Harvard University Press.

Verevis, C. (2006). Film Remakes. Edinburgh: Edinburgh University Press.

Waldhorn, A. (1972). A Reader's Guide to Ernest Hemingway. Syracuse, NY: Syracuse University Press.

Watts, E. S. (1971). Ernest Hemingway and the Arts. Urbana, IL: University of Illinois Press.

\section{Fonseca, Journal of Communication}

